\title{
El discurso político en la era digital. Donald Trump y su uso de Twitter
}

\author{
Political discourse in the digital era. Donald Trump and his use of Twitter \\ Silvia Gutiérrez Vidrio \\ Universidad Autónoma Metropolitana Xochimilco \\ sgvidrio@hotmail.com
}

\section{Resumen}

El propósito de este texto es formular algunas reflexiones sobre la manera en que hoy en día se produce, circula y recibe el discurso político en las diferentes plataformas digitales. Esto con el fin de captar los cambios que resultan del uso de dichas plataformas y sugerir algunos procedimientos metodológicos ad hoc para este renovado tipo de producción discursiva. Para caracterizar el discurso político en la era digital retomo como ejemplo la producción discursiva de Donald Trump en Twitter por ser la red sociodigital que más utiliza para emitir sus puntos de vista; en específico analizo algunos tuits que publicó sobre cuatro congresistas demócratas en julio 2019.

Palabras clave: democracia, discurso político, plataformas digitales, estrategias argumentativas, Donald Trump, Twitter

\section{Abstract}

The purpose of this text is to present considerations on the production, circulation and reception of political discourse as currently used in different digital platforms. These considerations aim to capture changes that result from the use of such platforms and to suggest some ad hoc methodological procedures for this recent type of discursive production. In order to characterize political discourse in the digital era, I take as an example Donald Trump's discursive production in Twitter, his preferred social media for expressing his political points of view; specifically I analyze some tweets he posted concerning four democratic congresswomen in July 2019.

Keywords: political discourse, digital platforms, argumentative strategies, Donald Trump, Twitter

Fecha de recepción: 25 de agosto de 2019 | Fecha de aceptación: 13 de enero de 2020

Cómo citar este artículo (MLA): Gutiérrez Vidrio, Silvia. "El discurso político en la era digital. Donal Trump y su uso de Twitter". Estudios del Discurso 6.1 (2020): 56-81. 


\section{Introducción}

- 1 tema del discurso político ha llamado la atención de varios investigadores
que se han dedicado al estudio de este género discursivo (Chilton y Schäffner; Charaudeau; Guespin, El análisis; Giménez; Gutiérrez; Verón, La palabra). Cabe recordar que por razones históricas, el discurso político fue uno de los primeros objetos de estudio abordados por aquellos investigadores que buscaban abrir el camino del análisis del discurso, en particular en Francia (Guespin et al.). Sin embargo, desde entonces hasta el día de hoy se han dado cambios importantes en los modos de aproximación en torno a los diferentes aspectos de este tipo de producción discursiva.

Un primer cambio que habría que mencionar es la propia noción de "la política" que ha sido objeto de varias reformulaciones; existen investigaciones que han contribuido a construir una nueva noción que incorpora una reflexión filosófica posfundacional sobre la diferencia entre la política y lo político que cuestiona la primacía del Estado y el poder para pensar el acontecimiento político (Arendt; Marchart; Rancière). También se han dado transformaciones en relación con la manera de hacer política; el fenómeno de la mediatización, es decir, la sumisión de la política a los formatos y lógicas propias del entramado técnico y operativo de las instituciones mediáticas, ${ }^{1}$ introdujo cambios importantes en los modos en que los políticos comunican sus ideas, programas y plataformas (Landi; Stromback; Verón, La mediatización).

A partir de este nuevo milenio, los discursos de los políticos han experimentado un nuevo proceso de mediatización: su producción y difusión en las redes sociodigitales. La evolución de los medios de información y, en particular, de las plataformas digitales, ha revitalizado tanto las prácticas discursivas en un nuevo formato del espacio público, como el análisis de éstas a la luz de interacciones que tienen un impacto cultural y político cuya magnitud apenas estamos comenzando a comprender.

${ }^{1}$ Existen otros términos utilizados para referirse a este fenómeno, por ejemplo la "videopolítica" o la "espectacularización de la política". 
En este texto me propongo formular algunas reflexiones sobre el modo en que hoy en día se produce, circula y recibe el discurso político en las diferentes plataformas digitales (Van Dijck) con el fin de describir los cambios que se han introducido y sugerir procedimientos metodológicos ad hoc a este nuevo tipo de producción discursiva, tomando como ejemplo algunos tuits de Donald Trump.

\section{Caracterización del discurso político: antecedentes}

Para caracterizar el discurso político que circula en las plataformas digitales es necesario proporcionar algunos antecedentes de cómo se ha conceptualizado y caracterizado este género para tener un parámetro de qué es lo que ha cambiado en esta era digital.

En primera instancia, habría que señalar que no es fácil caracterizar lo que constituye en sí mismo el discurso político. En la década de 1980 tanto Giménez como Verón señalaban una serie de dificultades para definirlo; una de ellas es que lo político y lo ideológico, dos de sus rasgos fundamentales, pueden encontrarse en casi todo tipo de discurso (Giménez, El análisis del discurso). Además, lo que se trata de caracterizar no es un tipo de discurso sino un campo discursivo, en el que es importante determinar los procesos de intercambio discursivo (Verón, $\mathrm{La}$ palabra). Ante estas dificultades, algunos investigadores se orientaron a identificar sus características entre las cuales se ubicaban las siguientes: es un discurso esencialmente argumentativo, tiene una base polémica, es estratégico y va dirigido más a convencer al indeciso y a ratificar al simpatizante que a convencer al adversario.

Si bien, a lo largo de varias décadas, el discurso político se definió a partir de una visión restringida de la política, dado que para describirlo conceptualmente no existía otro procedimiento al margen de una referencia a la producción discursiva articulada a las instituciones del Estado y a los líderes o partidos políticos (Giménez, El análisis; Guespin; Vérón, La palabra), esta manera de conceptualizarlo ha cambiado notoriamente en nuestros días.

Actualmente, existen varias concepciones de lo que es el discurso político; estas pueden ser agrupadas en dos modalidades: las restrictivas y las extensivas. En las 
restrictivas predomina una visión estrecha de la política que hace que este sea considerado como "el discurso producido dentro de la 'escena política', es decir, dentro de los aparatos donde se desarrolla explícitamente el juego del poder" (Giménez, El análisis 126), por ejemplo el discurso presidencial, el de los partidos políticos, el de la prensa política especializada, el emitido por los medios electrónicos en ciertos momentos.

Por otra parte, las concepciones extensivas optan por una noción ampliada de la política que da cabida a aquellos discursos que si bien no son emitidos desde los lugares institucionales donde se da el juego del poder, tienen una intención política, es decir, tienen como objetivo incidir en las relaciones de poder existentes. Desde esta concepción se consideran aquellas producciones discursivas que involucran el poder o su opuesto, la resistencia (Chilton y Schäffner), por lo que el discurso de la disidencia sería también considerado como político (Gutiérrez).

La noción de discurso político que adopto en este texto tiene que ver con una noción ampliada de la política que da cabida a las prácticas políticas, no solamente de los líderes políticos, sino también de la ciudadanía. Esta noción implica el análisis de las diferentes formas en que los líderes políticos tradicionales recurren a las tecnologías de la Internet y los discursos que ciertos sectores de la sociedad civil hacen circular en dichas tecnologías para participar en la política (Espino-Sánchez).

\section{De la plaza pública al ciberespacio político}

Durante un largo tiempo, la plaza pública era el sitio donde los candidatos y, en general, los partidos políticos comunicaban lo que eran, lo que pensaban; era allí donde las concentraciones mostraban la fuerza del partido, ya fuera por el número de asistentes o también por la dinámica discursiva e histriónica de los candidatos a diferentes cargos. Sin embargo, esto cambió con el advenimiento de los medios de comunicación de masas.

En la actualidad, la política se desarrolla en diferentes espacios y a través de diferentes medios. Por mucho tiempo los medios de difusión masiva se convirtieron en la principal fuente de información sobre política y en el vehículo de 
intermediación entre gobernantes y gobernados (Rovira, Activismo); sin embargo, hoy nos adentramos en una nueva era donde este contacto también se lleva a cabo en el seno del mundo cibernético a través de las redes sociodigitales, las cuales se han convertido en un camino rápido y directo para llegar a los habitantes y mantener un diálogo permanente con la ciudadanía.

El mundo de la política se ha incorporado a los nuevos desarrollos de la comunicación y partidos, líderes, representantes de cargos públicos o candidatos políticos se han trasladado, desde hace más de una década, al espacio digital encontrando un nuevo y provechoso canal para la difusión de sus mensajes que se suma al recurso de los medios tradicionales (Marín y Díaz).

Cabe señalar que Internet, al extenderse, compite en la difusión de información con el complejo político-mediático, pero lo hace con una lógica distinta: la de la red, que cambia radicalmente el proceso comunicativo en sus diferentes fases: la producción, la distribución y la recepción de la información. En la actualidad las audiencias se transforman en redes de personas que se conectan entre sí en un ambiente de abundancia informativa (Rovira, Activismo). Hoy se habla de usuarios conectados, de prosumidores y de autocomunicación de masas. Para Castells "La base de la comunicación de la sociedad red es la web global de redes de comunicación horizontal que incluyen el intercambio multimodal de mensajes interactivos de muchos a muchos, tanto sincrónicos como asincrónicos" (Castells 7).

Cada vez más, los conceptos de "ciberpolítica" o "política 2.0" son utilizados para explicar la forma en que los actores políticos (políticos, representantes y activistas sociales) usan los recursos de la internet social (Barassi). La "política 2.o" refiere al uso, por parte de los políticos, de las herramientas que ofrece Internet para potenciar su capacidad de estar en contacto con la ciudadanía (sin intermediarios), de escucharla y compartir sus opiniones. En lo que respecta a los ciudadanos, "la Política 2.0 es su capacidad de organizarse en redes a través de las herramientas 2.o para crear grupos de interés que acaben influenciando a los políticos y poderes públicos en sus decisiones" (Fages-Ramio 22).

Existen diferentes posturas en relación a si el surgimiento de comunidades electrónicas en realidad contribuye al fortalecimiento de la democracia o no. Inicialmente, se ubicaban dos visiones: quienes consideraban que el surgimiento dedichas comunidades sociales permite que los ciudadanos puedan deliberar 
informadamente acerca de tópicos de interés común, y quienes presentaban una visión del fin de la democracia y el surgimiento de un Estado sobreprotector basado en la supervivencia electrónica de los ciudadanos (Hague y Loader). Posteriormente surgieron voces más moderadas, que identificaron tanto fortalezas cuanto debilidades de dichas comunidades. Sin embargo, la gran interrogante que falta por responder es en qué medida los nuevos medios de comunicación contribuyen a un mayor y mejor ejercicio de la política y la participación ciudadana.

En lo que concierne a la política en las redes sociodigitales ${ }^{2}$ es necesario tener en mente las características esenciales de estas redes que es donde actualmente se producen y circulan gran parte de los discursos que tienen una intencionalidad política. Una de las revoluciones tecnológicas más importante para la política, al menos en las dos últimas décadas, es la extensión de las redes sociodigitales (Winocur) que son producto del desarrollo de las tecnologías de la información y comunicación que supone, entre otras cosas, una serie de interconexiones, de aplicaciones de Internet y el uso de diferentes dispositivos. El surgimiento, desarrollo y relevancia de este tipo de multiplataformas cibernéticas: Facebook, Youtube, Twitter, What App, Instagram, Snapchat, ha generado un intercambio de contenidos y narrativas que adquieren sentido según las prácticas y los contextos culturales.

Las redes digitales son una realidad en la vida de los ciudadanos, y la comunicación política se ha tenido que adaptar a este nuevo entorno. Estamos ante un nuevo modelo de hacer política. Esto es lo que algunos autores han llamado la tecnopolítica (Toret; Rovira, Tecnopolítica) que fomenta la participación ciudadana, aprovechando todo el potencial que las redes sociales ofrecen en una comunicación transversal y bidireccional.

Gracias a la participación y al trabajo colaborativo de millones de personas se habla de una Internet social (Web $2.0^{3}$ ), un espacio virtual que se configura a partir

\footnotetext{
${ }^{2}$ Las redes sociodigitales surgen a mediados de la década del 2000 como un nuevo fenómeno tecnológico y social. Éstas siguiendo a Kaplan y Haenlein, pueden ser definidas como "un grupo de aplicaciones de Internet construidas sobre los cimientos ideológicos y tecnológicos de la Web 2.o para permitir la creación e intercambio de contenido generado por los usuarios" (61).

${ }^{3}$ La llamada Web 2.0 comprende un amplio y relativamente vago conjunto de aplicaciones que usa a la World Wide Web (www) como interfase y que amplía considerablemente las posibilidades interactivas de este entorno de internet (Pérez).
} 
de diferentes aplicaciones como las redes sociales, los blogs, las wikis, etc. y que conlleva limitaciones, oportunidades y nuevos retos (Espino-Sánchez 42).

El intercambio de información y las opiniones de millones de personas, a toda hora y en todas partes, han llevado a una ampliación sin precedentes del espacio público. Este se ha constituido como una ágora digital donde cada usuario tiene las mismas posibilidades de acceso y el mismo derecho a ser escuchado que cualquier otro (Re), aunque también se ha analizado la formación de nodos más influyentes así como la posibilidad de manipularlos mediante operaciones específicas para aumentar la cantidad de seguidores y el impacto de los mensajes. A pesar de ello, los nuevos ciberespacios se definen como "una nueva concepción de la esfera pública, como un lugar de información, contestación, organización, discusión y lucha política" (Chaves-Montero 11). Esta se caracteriza por un empoderamiento de la ciudadanía, el desplazamiento de los medios tradicionales de comunicación, la entrada de nuevos grupos políticos en la escena política y la movilización del electorado (Chaves-Montero).

\section{Características del discurso político online}

La multiplicidad de códigos empleados en los sistemas modernos de comunicación ha llevado a los analistas del discurso político a ampliar el tipo de textos objeto de estudio, a no centrarse solamente en textos verbales y a incorporar el análisis de los mensajes multimodales. El análisis del discurso político también necesita ampliarse y contemplar los nuevos formatos que surgen y que circulan en la Web 2.o.

El discurso y su estructura han evolucionado con el paso del tiempo, ahora el contenido generado por las personas puede ser compartido con otros miles de usuarios y se crean comunidades de discusión en torno a múltiples temáticas. En el caso del discurso político lo que se observa es que los discursos extensos y por medio de la oratoria que solían realizarse en plazas públicas, aunque no se han extinguido completamente, ahora se realizan en las plataformas digitales, llegando así a millones de ciudadanos (López, Páez y Cuellar) con el uso de recursos y lenguajes híbridos que incluyen todo tipo de soportes transmediáticos (Scolari). 
Si bien se habla de cambios en la naturaleza misma del discurso político, habría que retomar aquellas características que tradicionalmente se asignaban a este tipo de discurso e identificar si estas han cambiado y en qué sentido y magnitud. Pero antes cabría aclarar que dependiendo del tipo de discurso político que se trate predominarán ciertas características; no es lo mismo un discurso electoral que tiene un carácter fundamentalmente persuasivo, que se orienta sobre todo a incitar al voto y convencer al indeciso, que el tipo de discurso que se emite para estar en contacto con la ciudadanía y crear una identidad común.

A continuación señalo algunas de las características que antes de la era digital se consideraban como propias de este tipo de discurso.

- Es un discurso en el que predomina el modo argumentativo.

El predominio de la función argumentativa, como varios investigadores han señalado (Bonnafous et al; Charaudeau; Giménez, El análisis) es la característica formal más evidente del discurso político. Argumentar consiste en aportar razones para defender una opinión y convencer a un receptor para que piense de una determinada manera. A pesar de algunos anuncios apocalípticos que auguran el fin de la argumentación con la digitalización (Sarlo), lo que se observa es que más que desaparecer, esta adopta nuevas modalidades. Si bien el formato de construcción del mensaje ha cambiado considerablemente, ya que por ejemplo Twitter tiene un límite de caracteres, por lo que las ideas y los mensajes deben ser breves, eso no implica que no exista argumentación. Ahora los actores políticos mezclan elementos de la argumentación racional con otro tipo de argumentos, por ejemplo la apelación a las emociones, el argumento ad hominen, ad rem y otros mecanismos peculiares de las plataformas digitales.

En Twitter los políticos han adaptado las estrategias argumentativas prototípicas de su discurso a esta plataforma virtual y han sabido explotar las posibilidades multimodales e intertextuales inherentes a la misma: el retuit, inclusión de enlaces y fotografías, introducción del eslogan electoral como hashtag, empleo estratégico de la mención @ usuario, para ponerlas al servicio de sus intenciones persuasivas (Padilla).

- Tiene una base esencialmente polémica.

Si toda argumentación es ya por lo menos implícitamente polémica, la argumentación política tiende a serlo de un modo superlativo y enfático (Giménez, El análisis). La polémica es un componente esencia del discurso político ya que 
como señala Gelas "es probablemente a propósito de la política que hablamos de polémica" (citado en Amossy 45). La polémica implica un debate alrededor de una cuestión de actualidad de interés público, que incluye cuestiones más o menos importantes de la sociedad de una cultura dada (Amossy). Esta implica divergencia y confrontación, rasgos fundamentales de la polémica que también son característicos de la argumentación. Además, la enunciación política parece inseparable de la construcción de un adversario (Verón, La palabra).

Este rasgo sigue caracterizando a los mensajes que circulan en las redes sociales, sobre todo en Twitter ya que mucho de lo que se publica en esta red, expresa una opinión sobre algo que es de interés público, que puede generar controversia y llevar a tomar posiciones antagónicas.

- Es un discurso estratégico, en la medida en que define propósitos, medios $\mathrm{y}$ antagonistas.

Es estratégico en varios sentidos, ya sea porque en su contenido mismo instaura metas o proyectos considerados valiosos para la convivencia social, en contraposición con otros que considera equivocados o indeseables, o en el sentido de que se elige un modo particular de enunciación en función del cálculo del efecto deseado (Giménez, Elementos 45). Precisamente porque el destinatario es muy amplio, el discurso político se caracteriza por ser estratégico y estar planificado, ya que el interlocutor es consciente de que está en juego su imagen social (ethos). Esto explica la necesidad. por parte de los políticos. de transmitir una imagen positiva de sí mismos, con el objetivo de que su discurso resulte lo más verosímil posible. También utilizan argumentos basados en hechos concebidos como ciertos e indiscutibles para el destinatario y refieren a valores democráticos como la libertad o la solidaridad (Padilla 423).

Si bien el discurso político online sigue siendo estratégico, en el sentido en que se busca que sea oportuno, planificado y aluda a ciertos valores compartidos, debido a su inmediatez y espontaneidad tiende a ser menos cuidadosamente planificado.

- Es un discurso que no se dirige tanto a convencer al adversario, sino a reconocer, distinguir y confirmar a los partidarios, y atraer a los indecisos (Giménez, El análisis).

Una característica esencia del discurso político es su particular dispositivo enunciativo, ya que es un discurso con destinación y funciones múltiples. 
Para Verón, en todo acto de enunciación política existen tres tipos de destinatarios. El prodestinatario (el partidario o adherente), aquel que comparte las premisas y el sistema de ideas barajado por el enunciador político. El contradestinatario (oponente o adversario), al que se busca descalificar en la enunciación política y con quién se establece la polémica. El paradestinatario, aquellos sectores de la ciudadanía que se mantienen, en cierto modo, "fuera del juego" y que, en los procesos electorales, son identificados como los "indecisos", que cuando votan deciden su voto a último momento (Verón, La palabra 17). A cada uno de los tres destinatarios corresponden tres funciones diferentes (refuerzo, polémica, y persuasión respectivamente) que operan de modo simultáneo, aunque con distinto grado de incidencia (Montero 320).

En el caso del discurso político online, uno de los cambios que se puede identificar es que ahora no se dirige tanto a convencer al indeciso, como anteriormente se hacía, sobre todo en el caso del discurso electoral, sino que dependiendo de la intencionalidad del locutor puede perseguir otros fines, por ejemplo, crear colectivos de identificación y por tanto, se dirige más a reforzar al prodestinatrio, o a polemizar con el contradestinatario. Además, actualmente el fenómeno de las "burbujas de afinidad", es decir, ese universo que nos envuelve al realizar nuestras búsquedas, como resultado de la personalización y de los mecanismos de los algoritmos, que seleccionan los resultados según la información previamente proporcionada por el usuario (Parisier), hacen que solamente nos lleguen aquellos discursos que han sido preseleccionados de acuerdo con nuestro consumo y preferencias.

Si bien, de acuerdo con diversos estudios, estas son las propiedades, que en diferente medida, describen al discurso político que circula en las plataformas digitales habría que agregar las siguientes: el lenguaje digital es hoy polisintético e integrador (pone en juego diversos lenguajes de la comunicación); se caracteriza por la multimodalidad (Kress y van Leeuwen), entendida como integración de diferentes recursos semióticos (imágenes, videos, audios); tiende a la coloquialidad y adopta los rasgos propios de los espacios digitales: la reticularidad, la interactividad, la convergencia y la hipertextualidad (Scolari); también hace uso de los recursos ortotipográficos como puntos suspensivos, exclamaciones y abreviaturas para incrementar la eficacia del discurso. 
Además, Internet y las redes sociales que despliega, permiten que la difusión de noticias falsas se magnifique en el espacio y en el tiempo lo que a su vez ha ocasionado que el fenómeno de las "fake news" (que siempre ha existido) adquiera notoriedad y relevancia social. Esto está también conectado con el tema de la posverdad que no es un sinónimo de mentira sino que describe una situación en la que, a la hora de crear y modelar la opinión pública, los hechos objetivos tienen menos influencia que las apelaciones a las emociones y a las creencias personales. La posverdad consiste en la relativización de la veracidad, en la banalización de la objetividad de los datos y en la supremacía del discurso emotivo (Zarzalejos).

\section{El análisis del discurso y la comunicación digital}

Los investigadores de diferentes disciplinas de las ciencias sociales han buscado métodos de investigación que permitan determinar lo que acontece en los escenarios digitales donde se desarrollan las prácticas que son objetos de análisis y en la diversidad de las comunidades virtuales (cf. Ardévol et al; del Fresno; Hine).

Las nuevas formas de accesibilidad, diseminación, movilidad, conectividad y ubicuidad que facilitan los nuevos dispositivos tecnológicos condicionan los criterios de la composición de textos, ya sean multi o monomodales. Para captar estas producciones, realizaciones o creaciones en forma de discursos, dinámicas, negociaciones, transacciones, etc., el análisis del discurso ha resultado ser un acercamiento metodológico de gran utilidad. Si bien los estudios sobre la naturaleza del discurso en redes sociales o plataformas online son muy recientes (cf. Crystal; Lara; Mancera y Pano; Sanmartín; Thurlow y Mroczek; Yus), estos evidencian un cambio de perspectiva que tiene en cuenta la complejidad de los nuevos discursos que les son inherentes a las plataformas digitales.

Pano y Moya, proporcionan un recuento detallado de gran parte de los estudios dedicados al análisis del discurso en los nuevos medios surgidos en la Web 2.0

${ }^{4}$ Estas refieren a información errónea o fabricada para lograr un beneficio y que es difundida en el campo mediático sin haber sido confirmada. 
publicados en los últimos quince años. Señalan que la variación lingüística es el concepto clave en torno al cual se mueve gran parte de los estudios atendiendo a aspectos como la interacción entre la comunicación escrita y oral en los discursos digitales, los rasgos socioculturales de los hablantes, y los factores contextuales y situacionales de la comunicación, sobre todo en chats, foros de debate y más recientemente, en redes socidigitales. Por otra parte, están los trabajos sobre la interacción en chats, correo electrónico, foros de debate, blogs y redes sociales digitales, ocupándose, principalmente de las relaciones entre oralidad y escrituridad en los mensajes, del carácter sincrónico y asincrónico de los medios y de la incidencia de este factor en la interacción comunicativa, de la construcción de la identidad y la imagen social en dichos canales, de la aparición de nuevos géneros discursivos en la Web, y de fenómenos pragmáticos como la (des)cortesía o la ironía verbal. También existen otros estudios que se centran en los conceptos de identidad y comunidad en los medios digitales, así como reflexiones en torno a la imagen social del individuo en Internet.

Si bien, como se muestra en este breve recuento, existen varios trabajos que investigadores del campo del análisis del discurso han realizado sobre las nuevas producciones discursivas en la Web 2.0, el ejercicio analítico, que a continuación presento, tiene que ver con una modalidad específica: el discurso político en Twitter. Existen ya algunos estudios que han analizado el discurso político en esta plataforma digital (Lara; Mancera y Pano; Padilla; Slimovich), sin embargo, estos se dedican fundamentalmente a estudiar el discurso electoral; en este caso me interesa mostrar cuáles son las propiedades de este género cuándo la intención del locutor no es directamente la captación de votos sino más bien establecer ciertos temas que pueden convertirse en tendencias (trending topics ${ }^{5}$ ) con el fin de disparar el debate en torno a ellos y diseñar o apuntalar una agenda.

\section{A manera de ejemplificación}

Dado que de las diferentes plataformas digitales Twitter es en la que el debate político es más intenso, he elegido esta red para ilustrar algunas de las nuevas

\footnotetext{
${ }^{5}$ Sobre el uso político de los trending topics ver por ejemplo: Fernández.
} 
características que adquiere el discurso político al ser producido en esta. Dado que Donald Trump es un asiduo usuario de esta red retomo un ejemplo de su producción discursiva.

Twitter ${ }^{6}$ se ha situado como la red sociodigital que más relevancia ha adquirido entre la clase política, jugando un importante papel para la difusión de sus mensajes, pero también es la red preferida por la ciudadanía para opinar o reaccionar sobre temas o cuestiones políticas en tiempo real de una manera directa, personal, fomentando, a su vez, la interactividad (Marín y Díaz). La funcionalidad de esta plataforma reside en ser una red que permite a sus usuarios conectarse y sostener conversaciones con personas de todo el mundo. ${ }^{7}$ Una de las sus características medulares es que desde su surgimiento se le consideró "una plataforma que empoderaba a los ciudadanos permitiéndoles dar a conocer sus ideas y emociones, ofrecía un lugar para el debate público y posibilitaba que determinados grupos o ideas concitaran la atención general" (Van Dijck 122).

Twitter es la red social predilecta de Donald Trump; sus polémicas con los medios, con los políticos, y con dirigentes de diferentes países, básicamente han surgido del uso intensivo que hace de ella. Esto ha impactado al mundo en general y se ha vuelto ya el signo de un presidente que parece gobernar por Twitter, el espacio virtual donde acusa, descalifica, dirime conflictos, toma decisiones a la vez que miente y se afirma en su discurso monolítico y monológico.

Para ilustrar el tipo de discurso político que Trump hace circular en Twitter he retomado un conjunto de tuits, ${ }^{8}$ sobre un tema polémico, que fueron altamente respondidos y retuitados a mediados de julio de 2019. Este tiene que ver con la polémica que Trump suscitó al atacar a cuatro congresistas demócratas de mino-

6 Para una descripción pormenorizada de Twitter consúltese Lara; Mancera y Pano; Van Dijck.

7 Además los usuarios pueden suscribirse a los tuits de otros y convertirse en "seguidores".

${ }^{8} \mathrm{El}$ recorte se debe a que lo que presento es una ejemplificación y no los resultados de una investigación previamente ya realizada, además me interesó retomar un tema que en el momento de redactar este texto, hubiera sido polémico, altamente respondido y retuitado. Cabe señalar también que lo deseable es que este ejercicio fuera complementado por el análisis de las publicaciones a las que estos tuits dieron lugar; sin embargo por cuestiones de espacio me limito al análisis de los tuits de Trump para mostrar el tipo de estrategias retórico-argumentativas que utiliza para producir su discurso en Twitter. 
rías étnicas: Rashida Tlaib, Ilhan Omar, Alexandria Ocasio-Cortez y Ayanna Pressley, representantes de los estados de Nueva York, Michigan, Minnesota y Massachusetts, respectivamente, en julio de 2019. Estos comentarios desataron una nutrida polémica al ser ampliamente tachados de racistas.

Estas congresistas se han caracterizado por ser muy críticas con el gobierno de Trump y por proponer ideas progresistas; están en contra de la venta de armas, los centros de detención de los migrantes, la relación de EUA con Israel, entre otras cuestiones. El viernes 12 de julio de 2019 tres de estas congresistas hablaron sobre las condiciones de un centro de detención que habían visitado en la frontera México-Estadounidense. Trump defendió a los agentes fronterizos y luego publicó una serie de tuits.

El 14 de julio, el presidente de EE.UU. usó Twitter para instar a las legisladoras demócratas conocidas como "The Squad" que "regresaran" a sus países de origen. La polémica empezó cuando Trump afirmó que ellas "vinieron de países cuyos gobiernos son una total y completa catástrofe", por lo que les sugirió que se "regresaran" a esos lugares.

Dada las limitaciones de espacio solo presento un breve análisis de las estrategias discursivas utilizadas por Trump en esta red sociodigital, por ello me limito a identificar aquellos recursos retórico-argumentativos utilizados en el nuevo formato que adopta este género discursivo online. Recurro particularmente al análisis argumentativo para detectar cómo y en qué medida Trump centra y concreta el tema de discusión, de qué modo define la posición que defiende; cómo elabora los argumentos de acuerdo con esta posición y provee las objeciones de los interlocutores todo esto en un entorno online.

Inicio con el análisis de una secuencia de tres tuits del 14 de julio que necesita ser analizada en su conjunto porque Trump utiliza en esta serie tres tuis para construir su mensaje. Si bien esta plataforma tiene un límite de extensión (140 caracteres), ${ }^{9}$ en algunos casos esta regla no es respetada (sobre todo por los políticos) y se

\footnotetext{
${ }^{9}$ Cabe aclarar que con fecha 27 de septiembre de 2019 Twitter amplio el número de caracteres a 280, esto como una medida experimental y para incentivar su uso de manera más activa (Jímenez).
} 
generan series mucho más extensas. Esta práctica podría ser considerada, ya en sí, como una estrategia argumentativa del locutor.

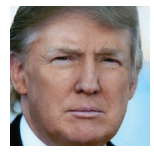

Donald J. TrumpCuenta verificada @realDonaldTrump ${ }^{10}$

So interesting to see "Progressive" Democrat Congresswomen, who originally came from countries whose governments are a complete and total catastrophe, the worst, most corrupt and inept anywhere in the world (if they even have a functioning government at all), now loudly..... 5:27 - 14 jul. 2019

73.945 respuestas, 48.904 retweets, 211.490 Me gusta

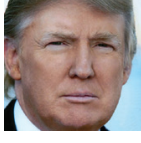

Donald J.Trump@realDonaldTrump 14 jul.

....and viciously telling the people of the United States, the greatest and most powerful Nation on earth, how our government is to be run. Why don't they go back and help fix the totally broken and crime infested places from which they came. Then come back and show us how....

32.719 respuestas, 39.236 retweets, 186.507 Me gusta

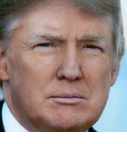

Donald J. Trump@realDonaldTrump 14 jul.

....it is done. These places need your help badly, you can't leave fast enough. I'm sure that Nancy Pelosi would be very happy to quickly work out free travel arrangements!

33.952 respuestas, 37.397 retweets, 188.882 Me gusta

Una primera característica sobre el discurso online que es necesario resaltar tiene que ver con el uso de los indicadores de me gusta y el retuit. Estos son indicadores importantes de las repercusiones y la legitimidad que puede tener un tuit. Esta especie de aceptación del contenido en cuestión, se evidencia en el gran

\footnotetext{
${ }^{10}$ Los tuits fueron tomados de la cuenta oficial del presidente Donald J. Trump (ver Trump).
} 
número de me gusta y retuits que tienen, como el caso del primero que obtuvo: 73.945 respuestas, 48.904 retweets, 211.490 me gusta.

Si uno trata de reconstruir la tesis que defiende Trump, en esta serie de tuits, se podría decir que es la de que no se puede decir a un gobierno cómo gobernarlo, si se proviene de países cuyos gobiernos son un total caos. Lo que llama la atención es que para sustentar esta tesis los recursos que utiliza no son argumentos basados en hechos sino más bien emplea una gama de recursos retórico-argumentativos para construir la imagen negativa de su adversario, para desafiar y descalificar los hechos que no le convienen y para defender su propia postura. Son precisamente estos recursos retórico-argumentativos, tales como el ataque al contrincante, el uso del humor, el uso de falacias, la burla, la apelación a los sentimientos colectivos, el ataque $a d r e m$, la pendiente resbaladiza y el interpelar directamente al prodestinatario o al adversario, los que analizo a continuación.

Ataque al contrincante. Una de las características esenciales del discurso político es su naturaleza polémica que es inseparable de la construcción del adversario. Teniendo en cuenta la naturaleza del discurso político, y más específicamente del presidente de una nación, es de esperar que el corpus aparezca el ataque al oponente político ya sea de manera directa o indirecta. Esto, cómo se observa en los tuits citados, es claramente identificable. Si bien no se refiere de manera explícita a cada una de las cuatro congresistas, por el contexto se sabe de quién está hablando.

La presentación negativa, y por tanto la deslegitimación, de las congresistas la realiza al presentarlas como personas que "provienen de países cuyos gobiernos son una completa y total catástrofe, lo peor, los más corruptos e ineptos de cualquier parte del mundo". El uso de palabras choque como catástrofe, corruptos, ineptos, predispone a su seguidor a tener una representación negativa tanto de sus "supuestos" ${ }^{11}$ países de origen, como de ellas. En ese ataque al contrincante está presente también la polémica la cual "se hace eco del discurso adverso socavando los fundamentos por todos los medios posibles, ya sea la negación, la reformulación orientada, la ironía, la deformación de las cuestiones" (Amossy 57). Trump hábilmente utiliza estos recursos para argumentar que ellas no tienen derecho a

\footnotetext{
${ }^{11}$ Cabe señalar que de las cuatro congresistas solamente una de ellas proviene originalmente de otro país.
} 
decirle al gobierno como gobernar al país. Esta presentación negativa del otro, tiene su contraparte: la autopresentación positiva; así presenta a los Estados Unidos como "la nación más grandiosa y poderosa de todo el mundo".

El uso del humor. Generalmente el humor es utilizado como elemento persuasivo. Es un fenómeno semántico y pragmático con un carácter estrictamente contextual ya que existen cuestiones que solamente son entendibles en el contexto cultural en que aparecen. Así la expresión: “¡Estoy seguro de que Nancy Pelosi estaría muy feliz de organizar rápidamente los arreglos de viaje gratis!" se puede reconocer el humor al implicar que la misma Nancy Pelosi ${ }^{12}$ no concuerda con sus ideas y estaría feliz de que se fueran.

El siguiente tuit del 15 de julio no forma parte de una secuencia.

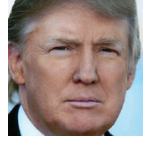

Donald J. Trump @realDonaldTrump

The Dems were trying to distance themselves from the four "progressives," but now they are forced to embrace them. That means they are endorsing Socialism, hate of Israel and the USA! Not good for the Democrats! 14:26 - 15 jul. 2019

35.149 Retweets, 137.530 Me gusta

Uso de falacias. En este tuit desde el punto de vista argumentativo lo que se identifica es una falacia, es decir, un argumento que parece válido pero en el fondo no lo es; el hecho de que los demócratas se ven forzados a abrigar a las congresistas no implica que adopten el socialismo, el odio a Israel a los UsA. Este enunciado se presenta como un aparente argumento pero su validez es débil o nula, además solo presenta una parte de la cuestión.

La burla. Este recurso, ligado estrechamente con el humor y la ironía, se emplea como elemento persuasivo pero tiene un carácter estrictamente contextual. Así cuando dice ¡No es bueno para los demócratas!, en cierta manera se está burlando de ellos al implicar que el hecho de apoyar a las congresistas les va a restar popularidad. Aquí también los signos de admiración son un indicador de dicha burla.

\footnotetext{
${ }^{12}$ Ha habido desacuerdos entre Nancy Pelosi, la Presidenta de la Cámara de Representantes de afiliación Demócrata, y las congresistas en cuestión, por la manera de responder a la agenda de Trump sobre todo en el tema de la migración.
} 
El discurso politico en la era digital. Donald Trump y su uso de Twitter

A continuación analizo otra secuencia de tuits emitidos el 15 de julio.

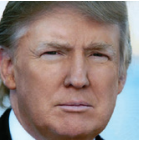

Donald J.Trump@realDonaldTrump

"We all know that $\mathrm{AOC}^{13}$ and this crowd are a bunch of Communists, they hate Israel, they hate our own Country, they're calling the guards along our Border (the Border Patrol Agents) Concentration Camp Guards, they accuse people who support Israel as doing it for the Benjamin's,.... 6:58 - 15 jul. 2019

37.183 Retweets, 159.934 Me gusta

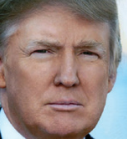

Donald J. Trump@realDonaldTrump 15 jul.

....they are Anti-Semitic, they are Anti-America, we don't need to know anything about them personally, talk about their policies. I think they are American citizens who are duly elected that are running on an agenda that is disgusting, that the American people will reject....... .

443 respuestas, 12.583 retweets, $48.476 \mathrm{Me}$ gusta

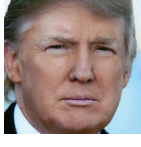

Donald J.Trump@realDonaldTrump 15 jul.

....What does it mean for America to have free Healthcare for Illegal Immigrants, no criminalization of coming into our Country - See how that works for controlling Immigration! They talk about Israel like they're a bunch of thugs, not victims of the entire region. They wanted...

5.505 respuestas, 22.851 retweets, 109.123 Me gusta

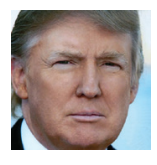

Donald J. Trump@realDonaldTrump 15 jul.

...to impeach President Trump on DAY ONE. Make them the face of the future of the Democrat Party, you will destroy the Democrat Party. Their policies will destroy our Country!” @LindseyGrahamsc Need I say more?

16.788 respuestas, 24.734 retweets, $118.176 \mathrm{Me}$ gusta

13 Se refiere a Alexandria Ocasio-Cortez, una de las cuatro congresistas demócratas.

$$
\text { Volumen } 6 \text { Número } 1
$$


Apelación a los sentimientos colectivos. Los políticos, y los ciudadanos en general, son conscientes de que la sociedad está muy preocupada y sensibilizada con ciertos temas, por lo que se sirven de ellos para hacer ver a sus destinatarios que tienen sus mismas inquietudes y preocupaciones. Esto les permite conectar con su audiencia, y al mismo tiempo activar su parte más sensitiva (Padilla). Así, cuando en el primer tuit se refiere a Alexandria Ocasio y a ese "puñado de comunistas" pone al centro de su argumentación el tema del odio "ellas odian a Israel, odian a nuestro país", una emoción designada, es decir, que él se las adjudica a ellas, sin embargo, el hecho de evocarla puede causar ese mismo sentimiento hacia ellas.

Argumento ad rem. A diferencia de la argumentación ad hominen, la argumentación ad rem va dirigida no contra la persona sino contra las cosas, los hechos. En el segundo tuit de esta secuencia se ubica este tipo de argumento, ya que ataca en este caso sus políticas, más específicamente su agenda, que tacha de "repugnante".

La pendiente resbaladiza sugiere que una acción iniciará una cadena de eventos que culminarán en un evento posterior no deseado, sin establecer o cuantificar las contingencias relevantes. Así cuando Trump enuncia en el último tuit: "Conviértanlas en la cara del futuro del Partido Demócrata, destruirán al Partido Demócrata. Sus políticas destruirán nuestro país" advierte que su presencia es dañina no solo para el partido demócrata sino también para el país. Además este argumento lo enuncia después de alegar que ellas "desde el primer día querían lograr la destitución del presidente".

Interpelar directamente al prodestinatario o al adversario. En el último tuit se puede ubicar una estrategia típica de Twitter, la de dirigirse directamente a alguien por medio del uso de la @usuario. Este mecanismo cumple tanto una función dialógica, al permitir jugar con las distintas voces del discurso, así como apelativa (Lara) establecer el contacto. En el tuit Trump interpela directamente a Lindsey Graham, Senador republicano de Carolina del Sur, uno de sus aliados quién también llamó a las congresistas a "bunch of communist". Al apelar a un compañero de partido (prodestinatario), utiliza este mecanismo, para reforzar las propias aserciones "necesito decir algo más". En este caso dicha apelación actúa como fuente argumentativa (Padilla), ya que pueden funcionar como un argumento de autoridad. 
El discurso politico en la era digital. Donald Trump y su uso de Twitter

\section{A modo de conclusión}

En este texto me propuse identificar los cambios que se pueden observar en el discurso político online, en comparación con las características esenciales de este género discursivo antes de la era digital y sugerir procedimientos analíticos ad hoc. La serie de tuits analizada, aun con las limitaciones de ser un mero ejemplo, permite afirmar que en el nivel de la materialidad discursiva las características tradicionales del discurso político (ser un discurso argumentado, polémico, estratégico) siguen presentes, aunque con ciertas particularidades.

En el nivel discursivo lo que más ha cambiado son las dinámicas discursivas ya que actualmente estas son muy parecidas a las conversacionales. Ahora el ciudadano ya no sólo escucha, sino que también habla, como una intervención en una conversación que puede ser respondida, es decir, existe un entrecruzamiento de innumerables voces con la apariencia de diálogo. Esto crea una situación híbrida en el continuum oral escrito, coloquial - formal (Padilla). Se trata de un discurso híbrido que comparte rasgos de la comunicación escrita y verbal y que es apoyado por contenidos multimediales. Esto, como he sugerido, no implica que la argumentación desaparezca. Existen formas breves de argumentación a través de la presentación de "microentimemas" o "microejemplos" que funcionan como disparadores temáticos del debate. Esto se combina con otros componentes de carácter lúdico y pasional (Slimovich). Son escritos mínimos en los que se precisa lo necesario, la acción, el espacio y el tiempo.

Otro de los cambios que también se observa es la presencia de una violencia simbólica, que anteriormente no era un rasgo esencial del discurso político, que se manifiesta en el lenguaje utilizado en las redes sociodigitales. Ahora se observa, por ejemplo, un uso descortés del lenguaje cuando se hace referencia al "exogrupo" para favorecer su propia imagen y para destruir la imagen de los adversarios. Si bien antes había descalificación se cuidaba el lenguaje utilizado y no se agredía verbalmente al adversario. En el caso de Trump tal parece que la estrategia de agredir verbalmente a sus opositores le funciona particularmente ya que no recibe sanciones o críticas de sus destinatarios privilegiados. Con respecto al uso de este tipo de lenguaje el tema de las "burbujas de afinidad" (Pariser) vuelve a ser relevante, en tanto que estas promueven los algoritmos de las plataformas digitales 
refuerzan prejuicios y exacerban el odio. Mientras los poderes estatales combinan desinformación y propaganda, los ciudadanos comunes responden a través de videos, memes y comentarios de odio.

También es importante mencionar que con el breve análisis presentado queda patente la necesidad de contextualizar adecuadamente el mensaje y estar habituado a las prácticas de este entorno para poder entenderlo en su totalidad y participar activamente en la discusión. No cualquiera usuario puede comprender y seguir la polémica si no dispone de conocimientos previos sobre la problemática en cuestión.

Otro tema que es importante resaltar es el de la apelación a las emociones que es relevante en el análisis del discurso político offline y online. En primer lugar, habría que defender la tesis que sostiene que las emociones poseen un marco de racionalidad y que también es posible argumentar por medio de las emociones (Gutiérrez y Plantin). Para estudiar la argumentación de la emoción, hay que saber cuál es el propósito que se persigue (la emoción que se quiere construir discursiva o argumentativamente). Esto implica poder reconocer cuando se está argumentando una emoción y cuando se está utilizando una falacia que no pretende argumentar sino más bien convencer sin aportar buenas razones apelando a elementos no pertinentes o, incluso, irracionales. En el caso de Twitter muy a menudo se utiliza el recurso a las emociones para construir una conexión emocional con la audiencia y también para provocar emociones en los internautas que los conmuevan y los lleven a adoptar una postura determinada.

En relación con los cambios en la circulación de los mensajes que se han llevado a cabo con el advenimiento de las plataformas digitales señalo los siguientes. Uno de los más visibles es la capacidad de una amplia circulación de los mensajes; otro es el desvanecimiento entre los papeles de emisor-receptor; también está el tema de la inmediatez y de la viralización de los contenidos, y a la vez la re-mediación (como los medios masivos extienden también y retoman lo que ocurre online, etc.). Respecto a esto último, las redes sociodigitales permiten esquivar las barreras de los medios informativos tradicionales favoreciendo una comunicación instantánea (Marín y Díaz). Esto se evidencia claramente en el uso intensivo de Twitter que realiza Trump ya que consigue que cada sus mensajes sean reproducidos fuera de la red y sean publicados por los medios impresos y digitales de todo el mundo. 


\section{Silvia Gutiérrez Vidrio}

Licenciada en Letras Modernas (Especialidad en Letras Inglesas) por la Universidad Nacional Autónoma de México; Maestra en Lingüística Aplicada de la Universidad de Lancaster, Inglaterra y Doctora en Sociología por la Universidad Nacional Autónoma de México. Profesora-Investigadora en el Departamento de Educación y Comunicación de la División de Ciencias Sociales y Humanidades de la Universidad Autónoma Metropolitana, Unidad Xochimilco. Sus líneas de investigación son el análisis del discurso, el estudio de las representaciones sociales y el tema de las emociones. En todas estas líneas cuenta con numerosas publicaciones.

\section{Obras citadas}

Amossy, Ruth. Apología de la polémica. Buenos Aires: Prometeo libros, 2017. Impreso. Ardévol, Elisenda; Estalella, Adolfo y Domínguez, Daniel (coords.) La mediación tecnológica en la práctica etnográfica. Gipuzkoa: Ankulegi, 2008. Impreso.

Arendt, Hannah. ¿Qué es política? Barcelona: Paidós, 1997. Impreso.

Barassi, Verónica. "Contested visions: Digital discourses as empty signifiers from the 'network to 'big data". Communication and the Public, 2016. Web. <https:// doi.org/10.1177/2057047316680220>

Bonnafous, Simone, Pierre Ciron, Dominique Ducard y Carlos Levy (eds.). Argumentation et discours politique. Rennes: Presses Universitaires de Rennes, 2003. Impreso.

Castells, Manuel. "Comunicación, poder y contrapoder en la sociedad red. Los medios y la Política". Telos 74 enero-marzo (2008): 13-24. Web. < https://red. pucp.edu.pe/ridei/files/2012/07/120704.pdf>

Charaudeau, Patrick. Le discours politique. Les masques du pouvoir. Paris: Vuibert, 2005. Impreso. 
Silvia Gutiérrez Vidrio

Chaves- Montero, Alfonso. "Introducción". Comunicación Política y Redes Sociales Chaves Montero et al. Sevilla: Ediciones Egregius, 2017. Web. <http://rabida.uhu.es/dspace/ bitstream/handle/10272/14553/Uso_efectividad_y_alcance.pdf?sequence=2 >

Chilton, Paul y Schäffner, Christina. "Discurso y política”. Teun van Dijk (comp.). El discurso como interacción social. España: Gedisa, 2000. 19-66. Impreso.

Crystal, David. Language and Internet. Cambridge: Cambridge University Press, 2001. Impreso.

Del Fresno, Miguel. Netnografía. Investigación, análisis e intervención social online. Barcelona: UOC, 2011. Impreso.

Espino- Sánchez, Germán. La política en internet, ¿de la mediatización a la convergencia digital? Convergencia Revista de Ciencias Sociales 65 (2014): 39-63. Web. <https://convergencia.uaemex.mx/article/view/998>

Fages-Ramió, Roc. "Actitud 2.0: la política más allá de los blogs". Monográfico IV Congreso Internet, Derecho y Política (IDP). Software social y Web 2.0: Implicaciones jurídico-políticas. IDP Revista Internet, Derecho y Política 7 (2008): 20-25. Web. < https://www.researchgate.net/publication/26544581_Actitud_20_ la_politica_mas_alla_de_los_blogs $>$

Fernández Rubiño, Eduardo. "Nuevas formas de cultura política: Podemos, un giro anómalo de las redes sociales". Teknokultura 12.1 (2015): 77-91. Web. <https:// doi.org/10.5209/rev_TK.2015.v12.n1.48886>

Giménez, Gilberto. "El análisis del discurso político-jurídico”. Poder, estado y discurso, perspectivas sociológicas y semiológicas del discurso político-jurídico. México: UNAM,1983. 122-151. Impreso.

Giménez, Gilberto. "Elementos para una teoría del discurso". El debate político en México a finales del siglo xx. Ensayo de análisis del discurso. México: Unam, Instituto de Investigaciones Sociales, 2018: 19-47. Impreso.

Guespin, Louis, Jean-Baptiste Marcellesi, Denise Maldidier, Denis Slatka. "Le discours politique". Langages, 6.23 (1971). Web. < https://www.persee.fr/issue/lgge_0458-726x_1971_num_6_23?sectionId=lgge_0458-726x_1971_num_6_23_2048> 
El discurso politico en la era digital. Donald Trump y su uso de Twitter

Gutiérrez, Silvia. "Discurso político. Reflexiones teórico- metodológicas". Versión. Estudios de Comunicación y Política 10 (2000): 109-125. Web.

Gutiérrez, Silvia y Plantin Christian. "Argumentar por medio de las emociones. La campaña del miedo del 2006". Versión. Estudios de Comunicación y Política 24 (2010):41-69. Web. < Gutiérrez, Silvia y Plantin Christian. "Argumentar por medio de las emociones. La campaña del miedo del 2006". Versión. Estudios de Comunicación y Política 24>

Hague, Barry y Loader, Brian. Digital Democracy: Discourse and Decision Making in the Information Age. Londres: Routledge, 1999. Impreso.

Hine, Christine. Etnografía virtual. Barcelona: voc, 2004 [2000]. Impreso.

Jímenez Cano, Rosa. “Twitter amplía el límite a 280 caracteres por mensaje”. El País. 17 septiembre 2017. Web. <https://elpais.com/tecnologia/2017/09/26/actuali$\mathrm{dad} / 1506399545$ _18901.html $>$

Kaplan, Andreas M. y Haenlein, Michael. "Users of the world, unite! The challenges and opportunities of Social Media". Business Horizons 53 (2010): 59-68. Web. < https://www.sciencedirect.com/science/article/pii/sooo7681309001232>

Kress, Gunther y van Leeuwen Theo. Multimodal discourse. The modes and media of contemporary communication. Londres: Arnold, 2001. Impreso.

Landi, Oscar. "Videopolítica y cultura". Diálogos de la Comunicación 29 (1991): 24-35.

Lara, Tiscar. "Competencia digital, nuevos medios, nuevos lenguajes, nuevos hablantes. Twitter y sus funciones comunicativas". Lenguajes y Texto 34 (2011): 39-45. Web. $<$ http://www.sedll.org/sites/default/files/journal/competencia_digital_nuevos_medios_nuevos_lenguajes_nuevos_hablantes._lara_t.pdf>

López, Laura; Páez, Julián; Cuellar, Arlex. "El discurso político mediado por ordenadores: análisis del discurso en las cuentas del presidente Juan Manuel Santos y del expresidente Álvaro Uribe Vélez en la red social digital twitter". Nexus comunicación 19 (2016): 110-129. <https://doi.org/10.25100/nc.voi19.666>

Mancera, Ana y Pano, Ana. El discurso político en Twitter. Análisis de mensajes que "trinan". México: Siglo XxI editores, 2013. Impreso.

Marchart, Oliver. El pensamiento político posfundacional. Buenos Aires: FCE, 2009. Impreso 
Marín, Pedro y Díaz, Aurora. "Uso de Twitter por los partidos y candidatos políticos en las elecciones autonómicas de Madrid 2015". Ámbitos. Revista Internacional de Comunicación, 2016 <http://www.redalyc.org/articulo.oa?id=16845702009>

Montero, Ana S. "Puesta en escena, destinación y contradestinación en el discurso Kirchnerista (Argentina, 2003-2007)". Discurso \& Sociedad 3.2 (2009): 316- 347. Web. < https://dialnet.unirioja.es/servlet/articulo?codigo=3738089>

Padilla, María S. "La argumentación política en twitter". Discurso \& Sociedad 9.4 (2015): 419- 444. Web. http://www.dissoc.org/ediciones/vo9no4/Ds9\%284\%29Padilla.pdf

Pano, Ana y Moya, Patricio. Una aproximación a los estudios sobre el discurso mediado por ordenador en lengua española. Tonos digital: Revista de estudios filológicos 30 (2016):1-30. <https://digitum.um.es/digitum/handle/10201/47991>

Pariser, Eli. El filtro burbuja. Cómo la red decide lo que leemos y lo que pensamos. Madrid: Taurus, 2017. Impreso.

Pérez, Gabriel. "La Web 2.0 y la sociedad de la información". Revista Mexicana de Ciencias Políticas y Sociales 56.212 (2011): 57-68. Web. <http://www.revistas. unam.mx/index.php/rmcpys/article/view/30400>

Rancière, Jacques. El desacuerdo. Buenos Aires, Nueva visión, 1996. Impreso.

Re, Facundo. "La política transmediática. Nuevas formas de participación ciudadana”. La Trama de la Comunicación 18 (2014): 33-51. Web. <https://latrama.fcpolit.unr.edu.ar/index.php/trama/article/view/466>

Rovira, Guiomar. Activismo en red y multitudes conectadas. Comunicación y acción en la era de Internet. México: Icaria-UAM Xochimilco, 2017. Impreso.

Rovira, Guiomar. "Tecnopolítica para la emancipación y para la guerra: acción colectiva y contrainsurgencia". IC Revista Científica de Información y Comunicación 16 (2019): 39-83. Web. <http://icjournal-ojs.org/index.php/IC-Journal/article/view/526>

Sarlo, Beatriz. La audacia y el cálculo. Kirchner 2003-2010. Buenos Aires: Sudamericana, 2011. Impreso.

Sanmartín Sáez, Julia. El chat. La conversación tecnológica. Madrid: Arco Libros, 2007. Impreso. 
El discurso politico en la era digital. Donald Trump y su uso de Twitter

Scolari, Carlos A. Narrativas transmedia. Cuando todos los medios cuentan. Barcelona: Deusto, 2013. Impreso.

Slimovich, Ana. "El discurso macrista en Twitter. Un análisis sobre la campaña para la reelección del Jefe de Gobierno de Buenos Aires". Revista de estudios políticos y estratégicos 2.1 (2014): 8-27. Web. $<$ https://revistaepe.utem.cl/articulos/el-discurso-macrista-en-twitter-un-analisis-sobre-la-campana-para-la-reeleccion-del-jefe-de-gobierno-de-buenos-aires/>

Strömbäck, Jesper. "Four Phases of Mediatization: An Analysis of the Mediatization of Politics". The International Journal of Press/Politics 13.3 (2008): 228-246<https://doi.org/10.1177/1940161208319097>

Thurlow, Crispin \& Mroczek, Kristine. Digital discourse: Language in the new media. Nueva York: Oxford University Press, 2011. Impreso.

Toret, Javier. Tecnopolítica. La potencia de las multitudes conectadas. El sistema red $15 \mathrm{M}$ un nuevo paradigma de la política distribuida. Internet Interdisciplinary Institute, Universitat Oberta de Catalunya, 2013. Impreso.

Trump, Donald. Cuenta oficial de Twiter: @realDonaldTrump. Web. <https:/twitter.com/realDonaldTrump/status/1150381395078000643>

Van Dijck, José. La cultura de la conectividad. Una crítica de las redes sociales. México: Siglo XXI editores, 2016. Impreso.

Verón, Eliseo. La mediatización. Buenos Aires: Facultad de Filosofía y Letras. Universidad de Buenos Aires, 1986. Impreso.

Verón, Eliseo et al. "La palabra adversativa". El discurso Político. Buenos Aires: Hachette, 1987. Impreso.

Winocur Rosalía. "La emergencia de esferas público-privadas en las redes sociodigitales". Redes Sociodigitales en México. Winocur Rosalía y José Alberto Sánchez (coords). México: Fondo de Cultura Económica, 2015: 62-80. Impreso

Yus, Francisco. Ciberpragmática 2.o. El uso del lenguaje en Internet. Barcelona: Ariel, 2010. Impreso.

Zarzalejos, José A. "Comunicación, periodismo y 'fact-checking'". Uno 27 (2017): 11-13. Web. <https://www.revista-uno.com/numero-27/comunicacion-periodismo-fact-checking/> 